\title{
Wideband millimeter-wave substrate integrated waveguide cavity-backed antenna for satellites communications
}

\author{
Najib AL-Fadhali ${ }^{1}$, Huda A. Majid ${ }^{2}$, Rosli Omar ${ }^{3}$, M. F. Ismail ${ }^{4}$, M. K. A. Rahim ${ }^{5}$, \\ Abdul Rashid O. Mumin ${ }^{6}$, B. A. F. Esmail ${ }^{7}$ \\ ${ }^{1,3,6,7}$ Faculty of Electrical and Electronic Engineering, University Tun Hussein Onn Malaysia, Malaysia \\ ${ }^{2}$ Faculty of Engineering Technology, University Tun Hussein Onn Malaysia, Malaysia \\ ${ }^{4}$ Centre for Diploma Studies, Universiti Teknologi Malaysia, Malaysia \\ ${ }^{5}$ Faculty of Electrical Engineering, Universiti Teknologi Malaysia, Malaysia
}

\begin{tabular}{|c|c|}
\hline Article Info & ABSTRACT \\
\hline Article history: & This paper presents a new type of wideband waveguide (SIW) cavity-backed \\
\hline Received Dec 28, 2019 & $\begin{array}{l}\text { patch antenna for millimeter wave }(\mathrm{mmW}) \text {. The antenna proposed applies to } \\
\text { applications of } 31-36 \mathrm{GHz} \text { Ka-band such as satellites communications. }\end{array}$ \\
\hline Revised Mar 6, 2020 & The SIW is intended with settings for particular slots. The antenna \\
\hline Accepted Apr 12, 2020 & $\begin{array}{l}\text { is constructed on Rogers RT5880 (lossy) with } 2.2 \text { dielectric constant, } 1.27 \\
\mathrm{~mm} \text { thickness, and } 0.0009 \text { loss tangent. It is simulated in the programming of }\end{array}$ \\
\hline Keywords: & $\begin{array}{l}\text { computer simulation technology (CST) Microwave Studio. The simulated } \\
\text { results show that the SIW antenna resonates across } 31 \text { to } 36 \mathrm{GHz} \text { bands, }\end{array}$ \\
\hline $\begin{array}{l}\text { Cavity-backed } \\
\text { Millimeter-wave }\end{array}$ & $\begin{array}{l}\text { which means that this new antenna covers all applications within this range. } \\
\text { The reflection coefficients in targeting range are below } 10 \mathrm{~dB} \text {. The antenna } \\
\text { achieves good efficiency and gain with } 80 \% \text { and } 8.87 \mathrm{dBi} \text { respectively. }\end{array}$ \\
\hline
\end{tabular}

This is an open access article under the CC BY-SA license.

SIW antenna

Wideband

\section{Corresponding Author:}

Huda. A. Majid,

Department of Electrical Engineering,

University Tun Hussein Onn Malaysia,

86400 Parit Raja, Johor, Malaysia.

Email: mhuda@uthm.edu.my

\section{INTRODUCTION}

Integrated substrate waveguide (SIW) built through two parallel rows of thru-holes in a metalized planar substrate as shown in Figure 1 ends with an attractive transmission shape due to its simplicity of manufacture and the ability to integrate planar with active circuits [1]. A lot of work has been done over the past few years to improve the efficiency of microwave and millimeter wave elements with minimal effort and low cost technologies. These include the Substrate Integrated Waveguides (SIWs), initially presented as laminated waveguides as indicated in the study of [1-4], which can be easily executed by creating regular PCBs. Since the presentation of SIWs or laminated waveguides, different components, interconnections and SIW-based circuits have been created and their merits justified compared to their counterparts in the milled waveguide or transmission line.

According to [5], SIW interconnects provide an excellent EMI for a broadband bandpass signaling medium, while traditional planar transmission lines are known as the bottleneck quality in broadband systems due to their limited bandwidth and high-frequency losses. Similarly, in the study of [6], the electrical field distribution in an SIW fills the volume within the waveguide interconnection and the surface currents propagate over the larger cross-section of the Waveguide walls, resulting in low losses, and the demand for multi-band and compact electronic systems is continuously increasing. This will require SIW technology to be used in future in highly integrated system applications. The SIWs formed the basis for the model as a new 
signal transmitting instrument of many circuit components. The SIW platform is now being redesigned to components such as resonator cavities and filters that use microstrip, stripline or waveguide technology. According to [7, 8], other SIW-based components, such as waveguide cavities, were directly integrated into the PCB platform, enabling significant cost reductions in the development and mass production of microwave oscillators. The high-quality factor in the waveguide cavities makes an excellent choice for the coupling frequency. It was investigated in the study of [9] that reconfigurable antenna provides a compact and flexible system. A number of reconfigurable antennas can toggle between narrowband. The SIW technique is a new and emerging microwave application and integration technique. SIWs enable the realization by means of double rows of metal vias connecting a patch with the ground plane of the typical rectangular waveguides in planar form in dielectric substrates. SIW equipment allows for the integration into a common substratum of active materials, static systems and antennas to which transfers and losses [10]. All wireless systems can be easily integrated into the SIW methodology, according to the substratum approach model. SIW technology incorporates the advantages of traditional microstrip patch such as low weight, high degree of miniaturization, low cost, and easy manufacturing whereas metal waveguides are distinguished by high power handling, total shielding, and low losses. Compared to open planar lines or solid metal waveguides, it has several advantages. First, as it is a closed configuration like a wave guide, it provides electromagnetic interference-free design. Common circuit board (PCB) technology can also be integrated easily into planar substrates [2]

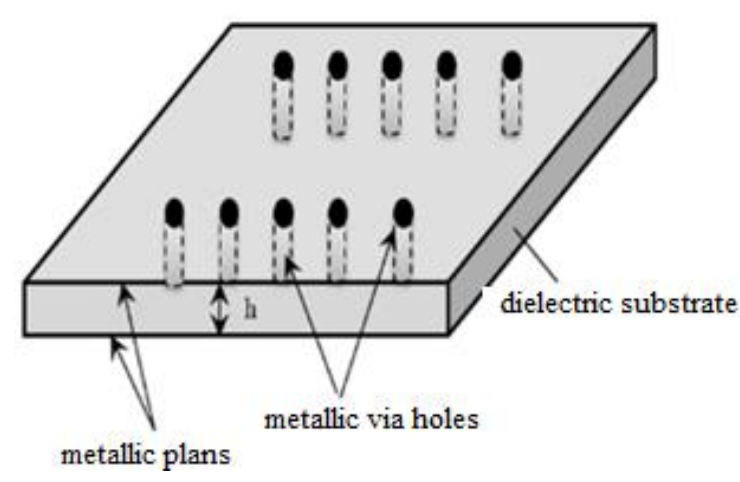

Figure1. Structure of SIW

Eventually, the new spreading architecture endows high-quality resonance factor with high-performance integrated resonators [3]. Regarding integrated SIW applications, many SIW, microstrip and coplanar transitions $[4,5]$ are investigated. Major knowledge has been gathered that a lot of work has been done to develop MMW communication over the past decade. The Federal Communications Commission (FCC) reserved $7 \mathrm{GHz}$ for unlicensed use in the 57-64 GHz band in 2001. The free spectrum, combined with advances in wireless communication technology, the opening of this large chunk of once perceived for expensive point-to-point connections, revived interest in this part of the spectrum. The possibilities immediately seen in this specific region of the spectrum include next-generation wireless personal area networks [7]. The unlicensed in Ka band has emerged as a worldwide short-range wireless system alternative such as WLAN with a data rate of about $1.5 \mathrm{~Gb} / \mathrm{s}$ allowing uncompressed video signal transmission between a video player and a TV to be a good choice for roughly Ka band unlicensed band application [8-9]. Various antenna models are proposed in this frequency band [10-11]. Due to its ease of manufacture, small size, planar structure and lightweight, SIWs are very attractive for millimeter applications, numerous papers have been published to model long-term microstrip antennas in the Ka-band community with efforts to build impedance transmission capacity [12-13]. Ka-band (26-40 GHz) satellites, communications satellites, uplink in either the $27.5 \mathrm{GHz}$ and $31 \mathrm{GHz}$ bands, and high-resolution, close-range targeting radars on military aircraft. Due to the expansion of materials, these structures are either muddled or lossful and the conventional planar encouraging used to couple vitality to the MPA, such as microstrip lines and coplanar waveguides. These structures suffer from conductive and radiation malfunctions on the mm-wave recurrence band, which decreases the overall ability of radio wire radiation, particularly in receiving wire display applications [14]. SIW is a planar rectangular wave guide used in many microwaves and mm-waves $[9,15]$ and radio recurrence $(\mathrm{RF})$ circuits, showing coplanar joining, minimal stress points of interest, high power handling. 
The SIW structure is introduced in this paper as a modern antenna with wideband $31-36 \mathrm{GHz}$ band covering radiation efficiency improvements in the $34-\mathrm{GHz}$ band compared to the current planar feeding structure. The Ka-band is attractive because of its multifold. In addition, data or bandwidth rates are never enough, while remote sight and sound circulation advertisements are constantly expanding, while wideband is a progressive power-a restricted band innovation awarded by FCC for its phenomenal 3.1-10.6 GHz unlicensed data transmission framework. Low discharge and hurried nature of wideband radio lead to increased security of correspondence and divider infiltration makes wideband frameworks suitable for unfriendly indoor conditions [16]. With low-cost and low-battery control-driven segments, it is possible to update the wideband motivation radio. Wideband can provide mixed media remote high-speed and is ideal for WPANs. In addition, one of the most difficult issues for wideband is that it is difficult for real nations to achieve universal operational coordination. In addition, IEEE standards are not accepted worldwide. Spectrum allocation, however, does not appear to be an issue in Ka-band for WPANs. This is one of the reasons why MMW is popular with the Ka-band. Another concern is system interference. The wideband includes the 2, 4, and $5 \mathrm{GHz}$ groups used for dynamically positioned a wireless local area network (WLANs), which intensify and disturb the impedance. Moreover, in Europe and Japan, there is this issue of framework impedance. Administrative bodies in these regions, as required by wideband execution, ensure current remote frameworks working in different areas. Global harmonization is possible around $34 \mathrm{GHz}$, but it is almost impossible to operate the regional broadband radio station in another area [17].

The 34-GHz radio, like the wideband microwave radio, is reasonable for high data and short separation executions but is less inclined to interfere with the frame than the wideband. Local locations, workplaces, meeting rooms, passages and libraries can find numerous applications [18]. It is therefore reasonable for home applications for sound/video transmission, work area association and support for cell phones. Mobile backhaul and mobile, multi-point computer links, wireless docking station, Gigabit Ethernet, file sharing, high-definition video streaming and ad hoc networks were measured by the interest shown by those driving CE and PC organizations in 31-35 GHz applications. Such three technologies are known to be the best in class, including video scanning, record sharing and remote Gigabyte Ethernet applications [19]

Due to the increasing demand for wireless broadband communication, $\mathrm{mmW}(30-300 \mathrm{GHz})$ technology has been under study for years due to its advantages of broadband working, anti-interference, simple miniaturization, etc. As a major element, the low-cost, high-gain and high-integration mmW antenna attracted considerable interest from industry and academia. Large amounts of $\mathrm{mmW}$ antennas have been recorded recently, such as microstrip antennas, slot antennas, dielectric resonator antennas, cavity antennas, but most of them have limited bandwidth and/or low efficiency of radiation, which are very critical in practice. A new form of rectangular patch antenna supported by SIW-fed cavity is suggested in this paper to improve bandwidth and efficacy of radiation. In contrast to other cavity-backed patch antennas, the cavity is designed to resonate in its mode, incorporating a broad operating band with patch resonance. The enclosed structure of the cavity may also suppress the surface wave and increase the radiation efficiency. Low cost, wide range, high radiation efficiency and simple coplanar integration features the proposed design.

Current wireless communication systems require wideband antennas to allow the operation of different devices at separate frequency bands. The standard requirements are light weight, low profile, low price, simplicity and reliability. Traditional high-gain wideband antennas include horn antennas, reflector antennas, and arrays of antennas that are either massive or have complex feeding networks. SIW resonator antennas have recently attracted the attention of researchers due to their high gain, usability, low price, etc. In this document, a wideband high-gain antenna (MMW) is created based on the SIW idea. Due to the allocation of radio astronomy and passive space service usage in adjacent bands, this range has challenges. This may require an in-band guard band to be introduced and makes it less feasible to combine in $26 \mathrm{GHz}$ and $28 \mathrm{GHz}$ with lower bands. It can be noted that this band is not assigned to the mobile service in the ITU radio regulations allocation table. Subsequent sections present the antenna design whereby SIW design phases is discussed. The subsequent sub-section presents the simulation results and discussions. Afterwards, the conclusion is presented.

\section{RESEARCH METHOD (ANTENNA DESIGN)}

The schematic of the proposed antenna appears in Figure 2, which demonstrates the position of the different slots that were investigated in the designed antenna, slots in the front, the distance between the consecutive vias, the diameter of via, length and width of the antenna layers. SIW arrangement made of metallic by means of via-hole arrays as previously stated, SIW is made of two parallel varieties of via holes delimiting the TE10 wave spread zone, as its cutoff frequency is only marked with the wave guide's width as long as the substrate thickness or waveguide height ' $\mathrm{h}$ ' is lower than ' Wsiw. The' Wsiw' parameter between the two arrays specifies the steady spread of the central mode, and the' D' and ' p' parameters are set to limit 
the loss of radiation as well as the loss of return [20]. Although SIW can be described as a regular rectangular waveguide by constant propagation, waveguide mode, and cutoff frequency and guided wavelength, it should be noted that SIW has some unpleasant physical qualities compared to traditional rectangular waveguides. Primarily, the geometric parameter' Wsiw' of the SIW is substantially larger than' b' given that the substrate thickness' b' has a physical constraint. Second, SIW's comparable waveguide width is not the same as 'Wsiw'.

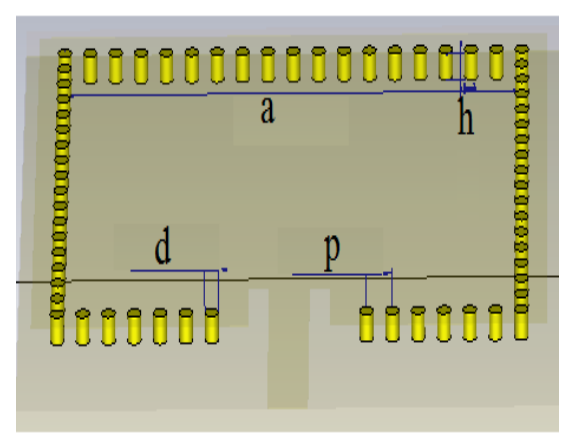

Figure 2. Configuration of the SIW synthesized by metallic via-hole arrays and its dimensions

Numerous trials and reforms have been conducted along these lines to confirm $\mathrm{a}_{\mathrm{eff}}$ estimate. An empirical condition is given by [16-17, 21-25].

$$
a_{\text {eff }}=a-1.08 \frac{d^{2}}{p}+0.1 \frac{d^{2}}{a}
$$

Whenever $\mathrm{d} / \mathrm{p}<1 / 3$ and $\mathrm{d} / \mathrm{a}<1 / 5$. SIW can be displayed by a rectangular wave guide with a comparable width and keeps losses of radiation at an insignificant level when its geometry parameters are metalized via whole measurement.

$$
\mathrm{d}<\left(\Lambda_{\mathrm{g}} / 2\right)
$$

The distance among the via holes is:

$$
\mathrm{p}<2 \mathrm{~d}
$$

SIW dimensions were constructed using the relevant equations that were adopted from the recent review of the literature while the length/width of the planned slots was focused on parametric research. Figure 3 shows the layout of the wideband SIW antenna following several parametric studies to test the effective length of the planned slots until the optimum location, length and width of the proposed slots is reached.

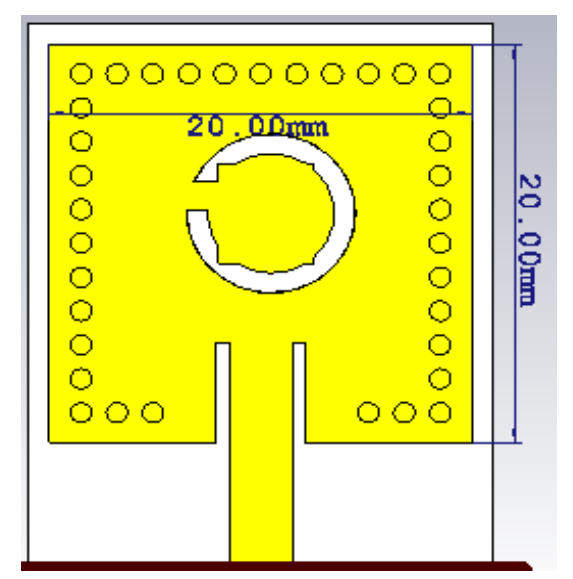

Figure 3. SIW antenna structure 
The dimension of the substrate used is shown in Figure 4. The wideband SIW antenna consists of a radiating element in the form of a front slot antenna, fed by a strip line to match the impedance to produce the best loss of return at the desired frequency. The antenna is constructed on Rogers RT5880 (lossy) with 2.2 dielectric constant, $1.27 \mathrm{~mm}$ thickness, and 0.0009 loss tangent. The design parameters are shown in Figure 4 and Table 1. Figure 4 shows the dimensions of the ground and substrate in more details as shown below. The antenna design and analysis has been done utilizing CST program. The geometry comprises of slots formed space and slots structure to understand the effectiveness of slots in terms of resonant frequency.

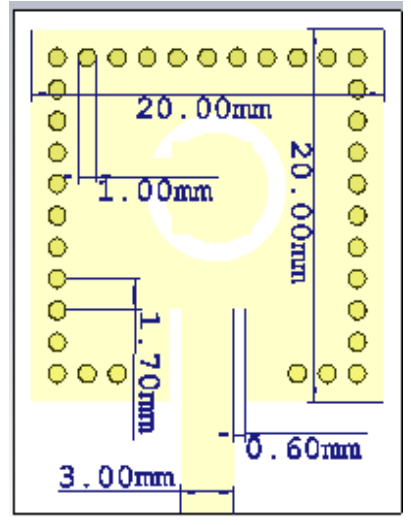

Table 1. The dimensions of ground and substrate

\begin{tabular}{llll}
\hline Type & W $(\mathrm{mm})$ & L $(\mathrm{mm})$ & $\mathrm{H}(\mathrm{mm})$ \\
\hline Patch & 20 & 20 & 0.35 \\
Ground & 22 & 27 & 0.35 \\
Substrate & 22 & 27 & 1.27
\end{tabular}

Note: The via diameter $(\mathrm{d})=1 \mathrm{~mm}$; The distance between 2

consecutive vias $=1.7 \mathrm{~mm}$

Figure 4. The substrate structure

\section{SIMULATION RESULTS AND DISCUSSIONS}

Performance of the proposed antenna was researched by utilizing the CST Microwave Studio programming. The streamlined measurement appears in Table 1.Reflection coefficient $(\mathrm{dB})$ demonstrates that almost in all range from $31-36 \mathrm{GHz}$ achieved lower than $-10 \mathrm{~dB}$, so in this condition make this antenna more reliable and robust to serve the application of satellites wireless communications. Figure 5 shows the resonant frequency of wideband which covers the whole range from $31-36 \mathrm{GHz}$.

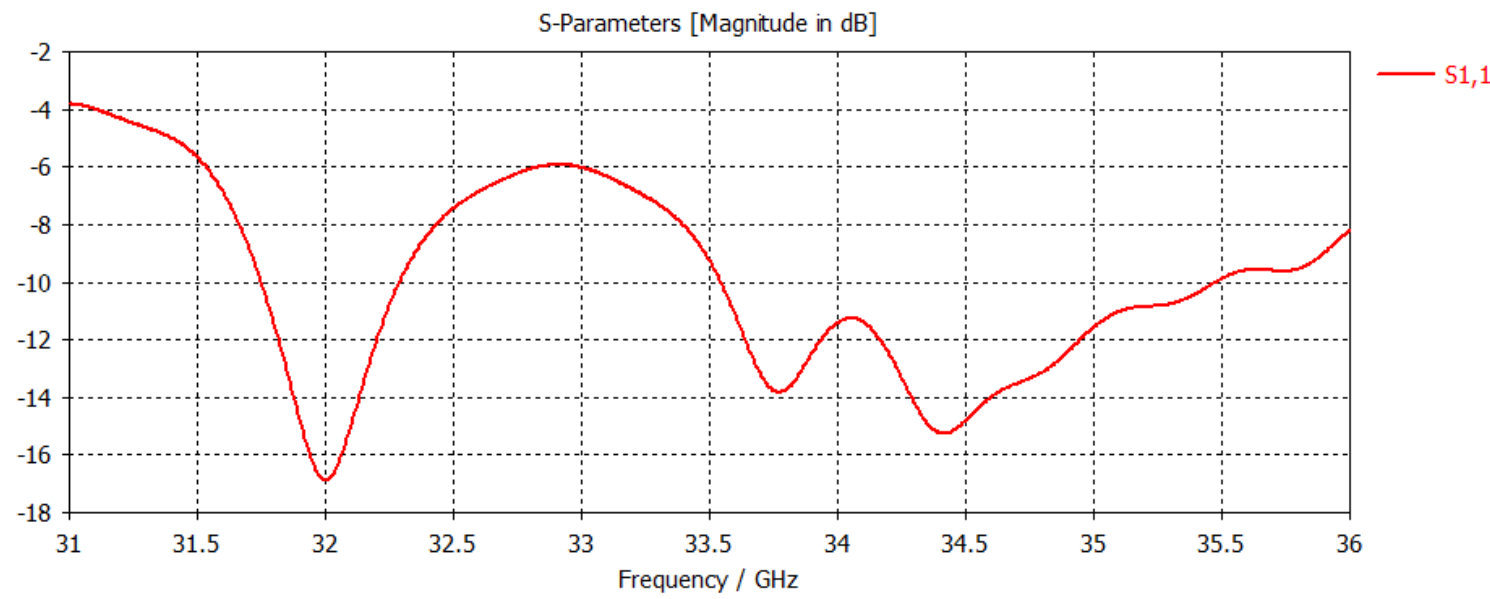

Figure 5. The resonant frequency of proposed SIW antenna

The distribution of the wideband SIW antenna's E-field shows that it resonates from the slots and vias wall confining the electromagnetic energy within the cavity as shown in Figure 6. The current distribution in the slot was studied to determine the maximum current in the slot. The radiation patterns observed in resonates frequency of $(33.5 \mathrm{GHz})$ is shown in Figure 7 . The antenna achieves good efficiency and gain with $80 \%$ and $8.87 \mathrm{dBi}$ respectively. 


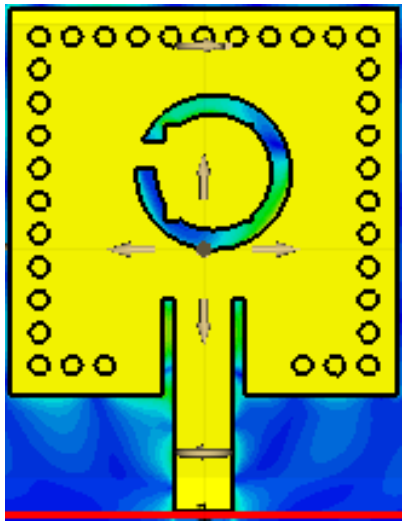

Figure 6. The current distribution from slots

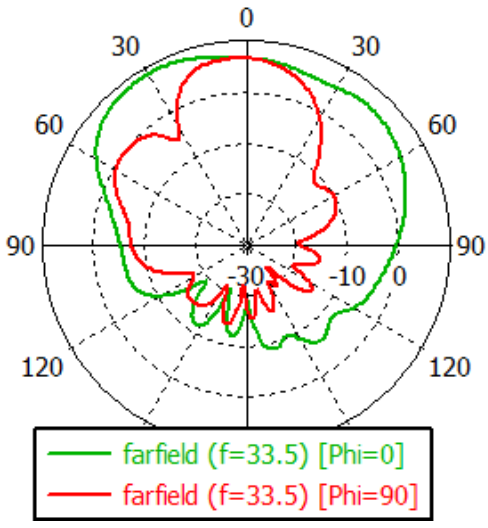

Figure 7. The radiation patterns of selected frequencies

\section{CONCLUSION}

This paper discusses the wideband SIW cavity slots antenna. A novel SIW design antenna base including smart wideband resonant antenna slots covering $32 \mathrm{GHz}$ and 33-35 GHz. The designed antennas were expected to support satellites Communications systems applications in the Ka band. It is simulated in the programming of CST Microwave Studio and the author recommends that the results of this study be improved to get deeper below the coefficients of reflection. At $80 \%$ and $8.87 \mathrm{dBi}$ respectively, the antenna achieves reasonable performance and benefits. In the future, real-time design, production and measurements will be carried out.

\section{ACKNOWLEDGEMENTS}

This work was supported by Ministry of Higher Education (MOHE), Faculty of Engineering Technology, Research Center of Applied Electromagnetics, Research Management Centre, Universiti Tun Hussein Onn Malaysia (UTHM) under Grant (Geran Tier 1 UTHM U923).

\section{REFERENCES}

[1] L. Sun, Y. Hou, Y. Li, Z. Zhang, and Z. Feng, "An open cavity leaky-wave antenna with vertical-polarization endfire radiation," IEEE Transactions on Antennas and Propagation, vol. 67, no. 5, pp. 3455-3460, 2019.

[2] S. Lee, S. Jung, and H-Y. Lee. "Ultra-wideband CPW-to-substrate integrated waveguide transition using an elevated-CPW section," IEEE Microwave and Wireless Components Letters, vol. 18, no. 11, pp. 746-748, 2008.

[3] Q. V. den Brande, S. Lemey, J. Vanfleteren, and H. Rogier, "Highly efficient impulse-radio ultra-wideband cavitybacked slot antenna in stacked air-filled substrate integrated waveguide technology," IEEE Transactions on Antennas and Propagation, vol. 66, no. 5, pp. 2199-2209, 2018.

[4] B. Scheiner, S. Mann, F. Lurz, F. Michler, S. Erhardt, S. Lindner, and A. Koelpin, "Microstrip-to-waveguide transition in planar form using a substrate integrated waveguide," In 2018 IEEE Radio and Wireless Symposium (RWS), pp. 18-20, 2018.

[5] H. Peng, X. Xia, J. Dong, and T. Yang, "An improved broadband transition between microstrip and empty substrate integrated waveguide," Microwave and Optical Technology Letters, vol. 58, no. 9, pp. 2227-2231, 2016.

[6] A. S. Cacciapuoti, K. Sankhe, M. Caleffi, and K. R. Chowdhury, "Beyond 5G: THz-based medium access protocol for mobile heterogeneous networks," IEEE Communications Magazine, vol. 56, no. 6, pp. 110-115, 2018.

[7] B. Bellalta, L. Bononi, R. Bruno, and A. Kassler, "Next generation IEEE 802.11 wireless local area networks: Current status, future directions and open challenges," Computer Communications, vol. 75, pp. 1-25, 2016.

[8] R. Arefi, R. D. Roberts, and M. E. Davis, "Regulatory issues and recommendations associated with use of highresolution drone detect \& avoid (D\&A) including for 5G applications," 2018 IEEE 29th Annual International Symposium on Personal, Indoor and Mobile Radio Communications (PIMRC), pp. 785-789, 2018.

[9] T. Yilmaz and O. B. Akan, "State-of-the-art and research challenges for consumer wireless communications at 60 GHz," IEEE Transactions on Consumer Electronics, vol. 62, no. 3, pp. 216-225, 2016.

[10] Y. Li and K-M. Luk, "60-GHz substrate integrated waveguide fed cavity-backed aperture-coupled microstrip patch antenna arrays," IEEE Transactions on Antennas and Propagation, vol. 63, no. 3, pp. 1075-1085, 2015.

[11] J. Liu, A. Vosoogh, A. U. Zaman, and J. Yang, "Design and fabrication of a high-gain 60-GHz cavity-backed slot antenna array fed by inverted microstrip gap waveguide," IEEE Transactions on Antennas and Propagation, vol. 65 , no. 4 , pp. $2117-2122,2017$.

[12] A. Attaran, R. Rashidzadeh, and A. Kouki, "60 GHz low phase error Rotman lens combined with wideband microstrip antenna array using LTCC technology," IEEE Transactions on Antennas and Propagation, vol. 64, no. 12 , pp. 5172-5180, 2016. 
[13] J. Saini and S. K. Agarwal, "Design a single band microstrip patch antenna at $60 \mathrm{GHz}$ millimeter wave for the 5G application," 2017 International Conference on Computer, Communications and Electronics (Comptelix), pp. 227-230, 2017.

[14] W. M. Abdel-Wahab and S. Safavi-Naeini, "Wide-bandwidth 60-GHz aperture-coupled microstrip patch antennas (MPAs) fed by substrate integrated waveguide (SIW)," IEEE Antennas and Wireless Propagation Letters, vol. 10, pp. 1003-1005, 2011.

[15] Y. Guo, "Designs of substrate integrated waveguide (SIW) and its transition to rectangular waveguide," Master Thesis, Auburn University, 2015.

[16] A-F. Najib, H. A. Majid, R. Omar, M. K. A. Rahim, S. H. Dahlan, A. Y. I. Ashyap, and B. A. F. Esmail, "Ultrawideband (50-60 GHz) mm-wave substrate integrated waveguide (SIW) antenna for 5G applications," 2019 IEEE 10th Control and System Graduate Research Colloquium (ICSGRC), pp. 58-61, 2019.

[17] F. Akhtar, M. H. Rehmani, and M. Reisslein, "White space: Definitional perspectives and their role in exploiting spectrum opportunities," Telecommunications Policy, vol. 40, no. 4, pp. 319-331, 2016.

[18] P. Shrivastava and T. R. Rao, "Performance investigations with antipodal linear tapered slot antenna on $60 \mathrm{GHz}$ radio link in a narrow hallway environment," Progress in Electromagnetics Research, vol. 58, pp. 69-77, 2015.

[19] N. Guo, R. C Qiu, S. S. Mo, and K. Takahashi, "60-GHz millimeter-wave radio: Principle, technology, and new results," EURASIP Journal on Wireless Communications and Networking, vol. 2007, no. 1, pp. 1-9, 2007.

[20] N. M. A. AL-Fadhali, H. A. Majiid, R. Omar, M. H. Mokhtar, and N. A. Mosali, "Frequency reconfigurable substrate integrated waveguide (SIW) cavity F-shaped slot antenna," Indonesian Journal of Electrical Engineering and Informatics, vol. 7, no. 1, pp. 136-143, 2019.

[21] N. AL-Fadhali, H. A Majid, R. Omar, S. H. Dahlan, A. Y. I. Asyap, S. M. Shah, M. K. A. Rahim, and B. A. F. Esmail, "Substrate integrated waveguide cavity backed frequency reconfigurable antenna for cognitive radio applies to internet of things applications," International Journal of RF and Microwave Computer-Aided Engineering, vol. 30, no. 1, pp. 1-16, 2020.

[22] A N. M. AL-Fadhali, H. A. Majidd, R. Omar, M. H. Mokhtar, S. M. Shah, Z. Z. Abidin, S. H. Dahlan, M. K. A. Rahim, N. A. Mosali, and B.A.F Esmail, "A compact ultrawideband (42-54 GHz) mm-wave substrate integrated waveguide (SIW) cavity slot antenna for of future wireless communications," Int. J. Innov. Technol. Explor. Eng. (IJITEE), vol. 8, no. 9, pp. 548-552, 2019.

[23] Z. C. Hao, W. Hong, H. Li, H. Zhang, and K. Wu, "A broadband substrate integrated waveguide (SIW) filter," 2005 IEEE Antennas and Propagation Society International Symposium, vol. 1, pp. 598-601, 2005.

[24] B. Xi, Y. Cai, Q. Xue, Y. Wang, S. Yang, and R. Zhang, "A simple design of SIW horn fed multibeam transmitarray antenna using transmission matrix approach," Microwave and Optical Technology Letters, vol. 62, no. 1, pp. 411-417, 2020.

[25] N. Al-Fadhali, H. A. Majid, R. Omar, M. K. A. Rahim, S. M. Shah, and B. A. F. Esmail, "Wideband (22-30 GHz) mm-wave substrate integrated waveguide (SIW) antenna for 5G applications," 2019 IEEE Conference on Antenna Measurements \& Applications (CAMA), pp. 1-4, 2019.

\section{BIOGRAPHIES OF AUTHORS}

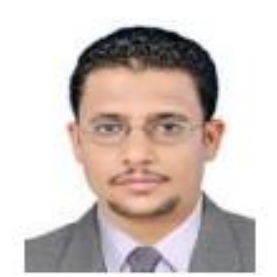

Najib AL-Fadhali received the B Eng. degree in Electrical Engineering (Telecommunications) with honours from Khartoum Unvirsity-Sudan, in 2008. He then obtained his M. Eng (Electrical Engineering) in 2012, at University of sience and technology in Sudan. He obtained PhD degrees in Technology Management in 2019, from Universiti Tun Hussein Onn Malaysia. Currently, he is a $\mathrm{PhD}$ researcher in Electrical and Electronic Engineering, Universiti Tun Hussein Onn Malaysia. His research interest in two areas of research which includes the areas of design Frequency reconfigurable SIW antenna as well as the research related to project technology management.

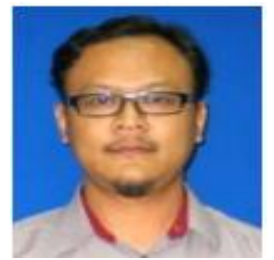

Huda A. Majid received the BEng degree in Electrical Engineering (Telecommunication) from Universiti Teknologi Malaysia, in 2007. He then obtained his MEng in 2010 and PhD degrees in Electrical Engineering in 2013, at Universiti Teknologi Malaysia. He is currently a lecturer in the Department of Electrical Engineering Technology, Faculty of Engineering Technology, Universiti Tun Hussein Onn Malaysia. His research interest includes the areas of design of microstrip antennas, small antennas, Reconfigurable antennas, metamaterials structure, metalaterial antennas and millimeter wave antennas. He has published over 50 articles in journals and conference articles.

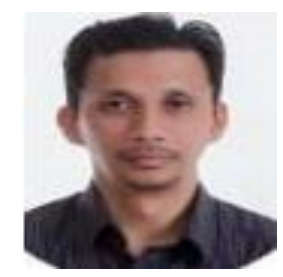

Rosli bin Omer received the B Eng. degree in Electrical Engineering from Universiti Teknologi Malaysia, in 1999. He then obtained his M. Eng in 2002 and PhD degrees in AUTONOMOUS SYSTEM in 2012, at university of leicester. He is currently an associate professor and the Dean in Electrical Engineering Faculty, Universiti Tun Hussein Onn Malaysia. His research interest includes the areas of design of Autonomous Systems, Control Systems System Identification, Robotics. 

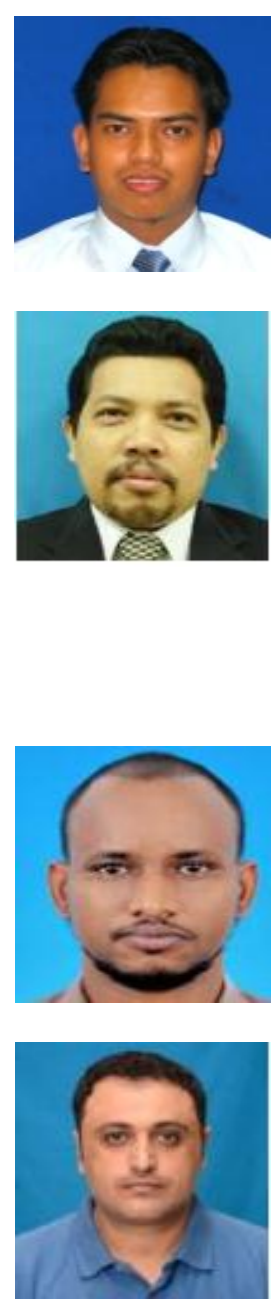

Muhammad Faizal Ismail received the B Eng. degree in Electrical Engineering (Telecommunications) with honours from Universiti Teknologi Malaysia, in 2009. He then obtained his M. Eng (Electrical Engineering) in 2011, at Universiti Teknologi Malaysia and also as ongoing PHD at same university. His research interest includes the areas of design of electromagnetic band gap (EBG) structure, microstrip antenna and pattern reconfigurable EBGs antenna.

Mohamad K. A. Rahim received the BEng degree in Electrical and Electronic Engineering from the University of Strathclyde, United Kingdom, in 1987. In 1989, he joined the Department of Communication Engineering, Faculty of Electrical Engineering Universiti Teknologi Malaysia (UTM), Kuala Lumpur, as an Assistant Lecturer A. He obtained his MEng degree from the University of New South Wales, Australia, in 1992 and PhD degree in Electrical Engineering from the University of Birmingham, United Kingdom, in 2003. He is the Professor in RF and Antenna at Faculty of Electrical Engineering, Universiti Teknologi Malaysia. His research interest includes the areas of design of dielectric resonator antennas, microstrip antennas, small antennas, microwave sensors, RFID antennas for readers and tags, multifunction antennas, microwave circuits, electromagnetic bandgap, and artificial magnetic conductors. He has published over 200 articles in journals and conference papers.

Abdul Rashid Omar Mumin was born in Mogadishu, Somalia in 1986. He received a BEng degree (with honors) in Electrical and Electronic Engineering from Universiti Tun Hussein Onn Malaysia (UTHM) in 2013, the MSc degree in Electrical Engineering from Universiti Tun Hussein Onn Malaysia (UTHM) in 2015. He is currently working towards his PhD at the Faculty of Electrical and Electronic Engineering, Universiti Tun Hussein Onn Malaysia (UTHM). His research interests include antenna design, microwave devices and wireless communications

Bashar A. F. Esmail received the BEng degree in Electrical Engineering (Telecommunications) with honors from Ibb University-Yemen, in 2008. He then obtained his MEng (Electrical Engineering) in 2016 from Universiti Tun Hussein Onn Malaysia. He is currently pursuing the $\mathrm{PhD}$ degree in Electrical Engineering at Faculty of Electrical and Electronic Engineering Universiti Tun Hussein Onn Malaysia. He has authored or coauthored a number of journals and proceedings. His research interest includes the areas of design of metamaterial structures, millimeter wave antenna, and reconfigurable antenna. 